\begin{tabular}{|c|c|c|c|}
\hline$\Omega$ & (1) & $\equiv$ & (2) \\
\hline $\begin{array}{l}\text { M. Fletcher }{ }^{1} \\
\text { K. Rabe }{ }^{2}\end{array}$ & $\begin{array}{l}1 \text { Chair, European Lung } \\
\text { Foundation } \\
2 \text { President, European } \\
\text { Respiratory Society }\end{array}$ & $\begin{array}{l}\text { The Athenaeum } \\
10 \text { Church Street } \\
\text { Warwick } \\
\mathrm{CV}_{34} 4 \mathrm{AB}\end{array}$ & m.fletcher@educationforhealth.org \\
\hline
\end{tabular}

\title{
World Spirometry Day 20I2: the highlights so far
}

At the time of writing this piece, World Spirometry Day (WSD) has just past and events have started to take place around the world in support of this global awareness campaign initiated by the Forum of International Respiratory Societies (FIRS). A previous Editorial in Breathe described the aims and scope of WSD2O12 []], and this current editorial will provide a snapshot of the campaign launch and some of the outstanding and inspirational events held. This editorial will also give details and thanks to some of the many Lung Champions who gave their time and names to WSD2012. Full details of the entire WSD2012 campaign will be available and published in a subsequent issue of this journal.

\section{The faces of WSD}

The concept of the WSD2O12 Lung Champions was to give a face and a voiceto peoplewith lung disease who havemanaged to overcometheir condition to achieve in sport or exercise. The hope was that these individuals would inspireothers like them and the publicto embrace exercise and appreciate its importance to lung health.

In recognition of his status as an international sporting champion and inspiration to others with lung conditions, the 2012 ELF award will be presented to Olaf Tufte at the European Respiratory Society Annual Congress. In addition, Alex Supple will be present to receive a certificate on behalf of all the Lung Champions for overcoming their lung conditions to succeed in sport and for being such a key partoftheWSD2O12 comapign.

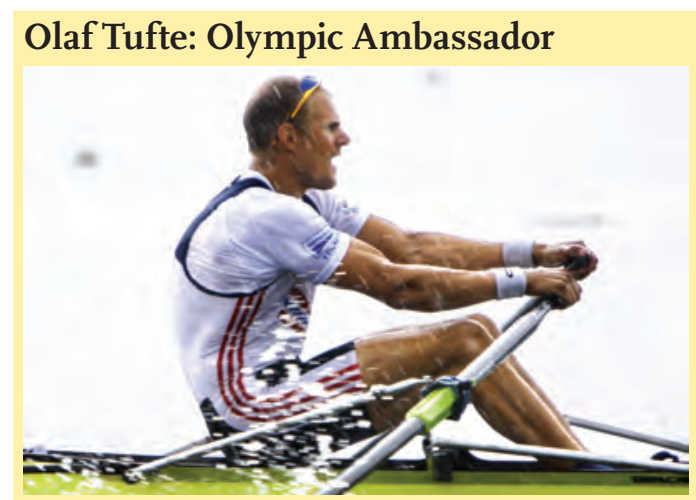

At the outset of this project, it seemed hard to imagine that an Olympian, be them past or present, would be willing or have the time to support WSD2012. It was therefore a surprise and a delight when Norwegian Olympic rowing champion Olaf Tufte agreed to spearhead the campaign.

Olaf competed in his 5 th Olympic Games at London 2012. Few rowers have competed in 5 Olympics, and even fewer have competed four times in the single sculls race during the Olympics. He has won two gold medals and one silver medal in Olympic competitions so far, and has contended for a fourth medal in 2012 (at time of print the results were not known).

Olaf's achievements put him at the pinnacle of the sport and place him in the small group of the sport's most-admired athletes. He has reached the top of his game, despite having asthma. Taking time out from his busy training schedule for the Olympics to support the campaign was a big ask and we thank him for his commitment.
Statement of Interest None declared 
Kjeld Hansen: "Running free" with asthma

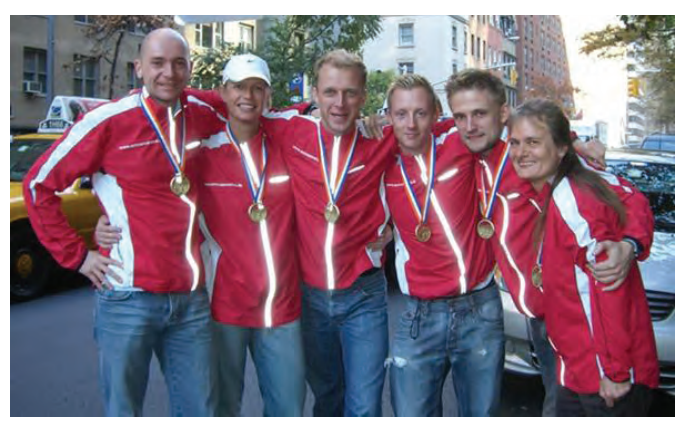

Kjeld Hansen is an asthmatic from Denmark who has always been keen to achieve in sport but has felt prohibited by his asthma. Kjeld, with a group of five others experiencing a range of moderate partly controlled asthma, from time to time uncontrolled asthma, decided to prove that asthma would not stop them and complete a marathon. They were treated for their asthma and trained by a professional coach. After 9 months of focused effort, all six were able to complete a full marathon in New York City, USA, without extra medication.

Kjeld told us: "Before I took part in the New York marathon, I did lose confidence in my own ability to perform in sports. It was hard to motivate yourself to train when your $100 \%$ is no match for a nonasthmatic person.

"During training for the marathon, I felt my confidence grow. On the day of the race, I knew I was about to embark on something I had felt was impossible only a year before. When the starter's signal sounded and we were off to the VerrazanoNarrows Bridge I could not believe it. It felt surreal to consider myself on equal terms with all these other runners.

"I feel that the New York City Marathon was my cure. I find that gaining control of my asthma has opened me up towards a new and much more sustainable life style, where I can control my own health to a much larger degree than before."

Jean Rommes: Passionate about exercise despite having COPD

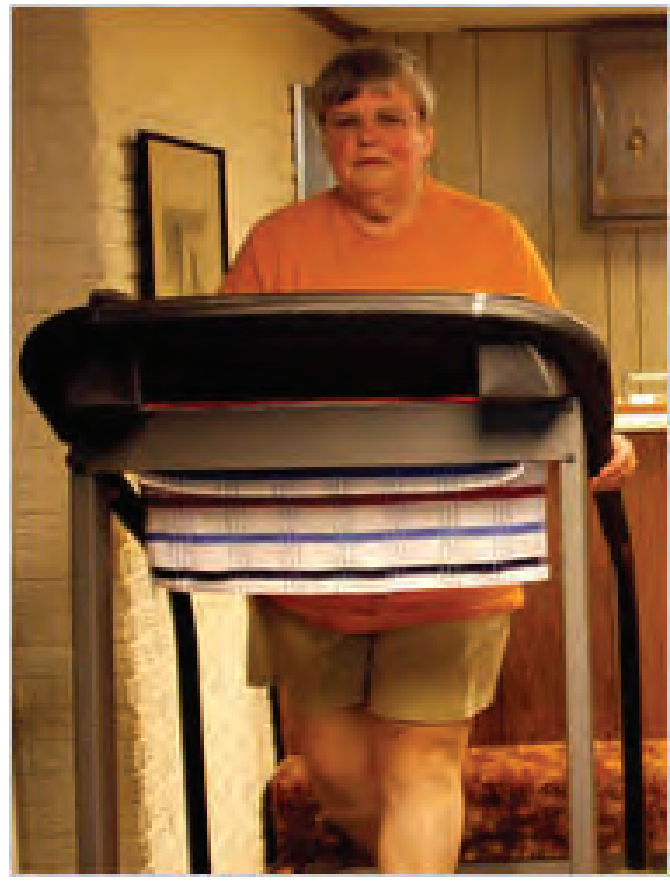

Jean from the USA began smoking when she was 18 and thought smoking was "cool". 30 years later, she finally stopped when she realised that she was organising her day around chances to smoke. She was concerned by how difficult she was finding it to breathe and decided to go to the doctor. At first, the doctor told her she had asthma but after a spirometry test and other diagnostics, Jean was eventually diagnosed with severe COPD in 2000.

As well as COPD, Jean has type-2 diabetes. Her doctor advised that losing weight would help ease the symptoms of both conditions. Jean decided to give it a try and began using an exercise bike, walking on a treadmill, lifting weights at a gym and eating a healthier diet.

By 2004 Jean felt a great improvement. She went from needing oxygen 24 hours a day to using it only for sleeping and, by 2005 , she no longer needed oxygen at all. Jean was able to lower the doses of her inhalers and diabetes medicines. She also lost 100 pounds and got a whole new wardrobe!

Jean continues to exercise regularly, starting everyday with 45 minutes on the treadmill. She exercises enough to make her heart rate rise whilst wearing a blood oxygen monitor to check her oxygen level doesn't get too low.

"I maintain my exercise routine pretty religiously, because it allows me to continue to do all these interesting and exciting things. Exercise is absolutely essential and it's essential to start it as soon as you know you have COPD. My mantra is: exercise not only lets me live, it enables me to have a life!" 
Alexander Supple: Rugby player and severe asthma sufferer
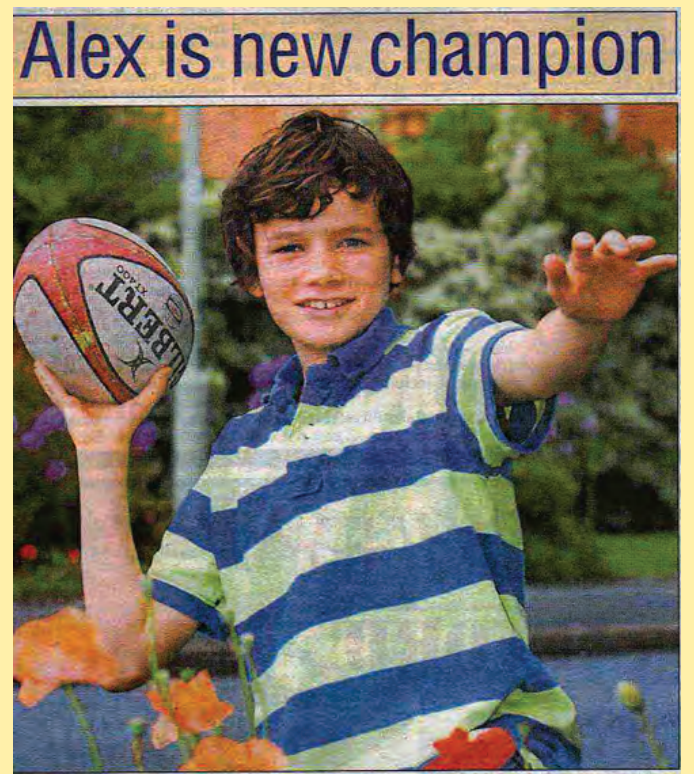

Alex Supple, 11, has been made a lung champion by the European Lung Foundation. A BRAVE 11-year-old boy from Newport has despite having a long term lung conditio been made a lung champion' after refusing which affects their breathing.

let his asthma get the better of him. "Inow know the difference between whe Paul Catholic Primary School in Newport, asthma attack. I enjoy sport and competin has been given the title by the European so if I didn't learn how to cope with $m$ m

\section{The essence of WSD}

WSD2O12 was about raising aware of lung health, increasing people's knowledge of spirometry, getting people interested in testing their lungs, and advocating for the benefits of exercise for all. FIRS invited all respiratory professionals to take part in whatever way they could; and hundreds of you responded. Although we are unable to list all of the amazing contributions that have taken place, some examples of events are listed below to give others a taster of the effort and commitment invested by so many. Our thanks go out to everyone who held an event and made it possible.

\section{Capitalising on the sports theme}

This year's WSD message about the importance of exercise for lung health was spread at sporting events and by sports personalities across the world.

50 people volunteered to be trained in spirometry and help to perform 2,000 spirometry tests during a lung testing event at the Comrades Marathon in South Africa. The WSD message of lung health and exercise has also been raised at the Roland Garros tennis tournament in France, by themed campaigns in Portugal and Latvia, by sports personalities in the Czech Republic and Poland, the national senior footballer Vladimir Kinder in Slovakia, at the Wenlock Games in the UK (which is the birthplace
Alex has struggled with his asthma since the age of 2, along with a wide range of food allergies. $\mathrm{He}$ is on a severely restricted diet and daily asthma medication to manage his condition. Despite his asthma being exercise-exacerbated, he has successfully played rugby in the first team for his local club, Newport (Salop), UK, since he was 6 . Now 11, Alex has developed into a skilful player over the years whilst valiantly struggling with his asthma.

David Supple, Alex's father, said:

"Despite his need to often come off the pitch to do his inhaler mid-match (even the occasional bout of oxygen on the sidelines is needed when his symptoms flare) he just battles through.

"I don't think any of his team mates quite realise how bad his asthma has been over the years, and he certainly makes no mention of it, he just displays an innocence and an acceptance to play the game and be part of his team.

"Whilst we recognise that many children suffer from much more severe levels of the condition, Alex still displays that humbling level of grim determination so typical of children with a longterm health condition."

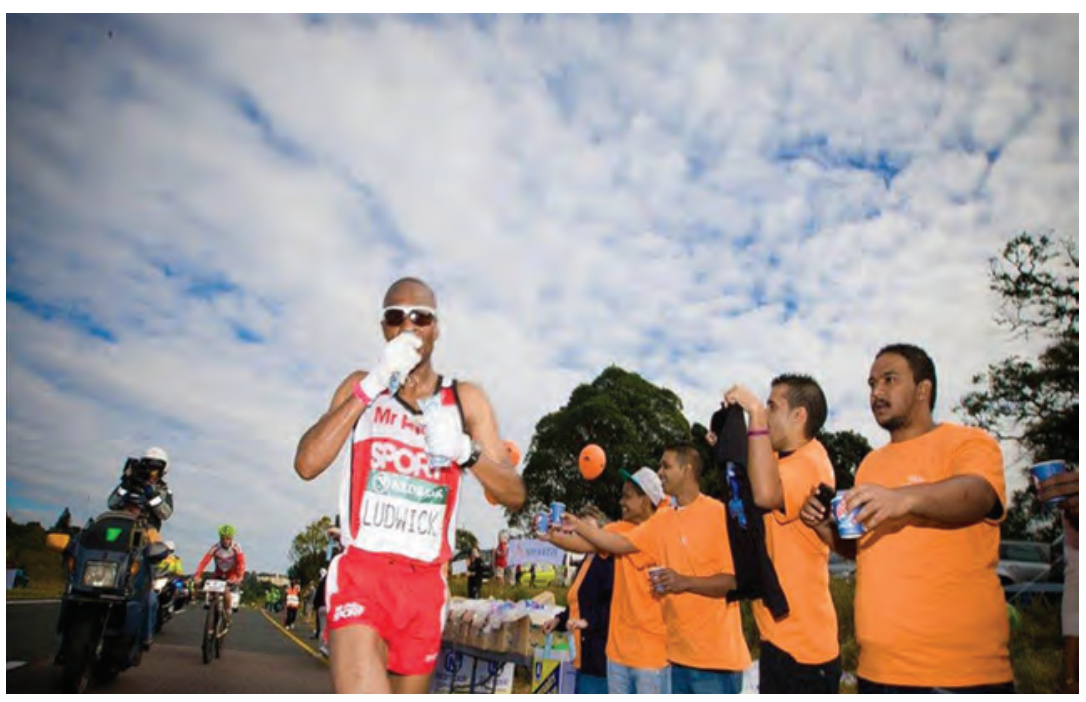

The Comrades marathon, South Africa

of the modern Olympics), a Nordic walking event in Russia, the Perugia marathon in Italy and by the Czech champion tennis player Petra Kvitova and cross country skier Lukas Bauer. In Southampton, UK, team GB divers came along to have their lungs tested. At events worldwide, exercise taster sessions have been offered with Lung Champions showing how exercise can be enjoyed safely despite having a lung condition. Events have also been run in gyms across the world and members of sports clubs have come along to have their lungs tested at other events. 
Educating professionals

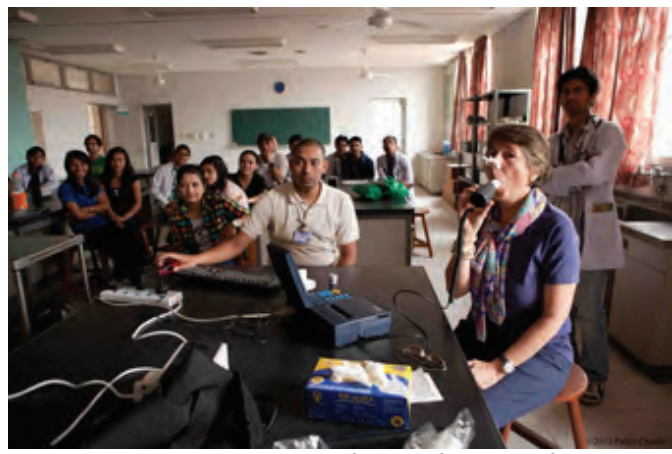

Spirometry training in Kathmandu, Nepal

In many countries, the WSD focus was to educate professionals about spirometry, how to perform a test, how to interpret the results and how to treat the patient afterwards. Spirometry equipment is often too expensive for health professionals in lowincome countries to purchase, but training helps raise their awareness of the method and airflow symptoms of lung disease. It was the first time that a spirometry training event has been held in Kathmandu, Nepal. The organisers emphasised the need for spirometry testing to be available to the public, but to achieve this health professionals must first know how to perform the test properly.

\section{Coordinating nationally}

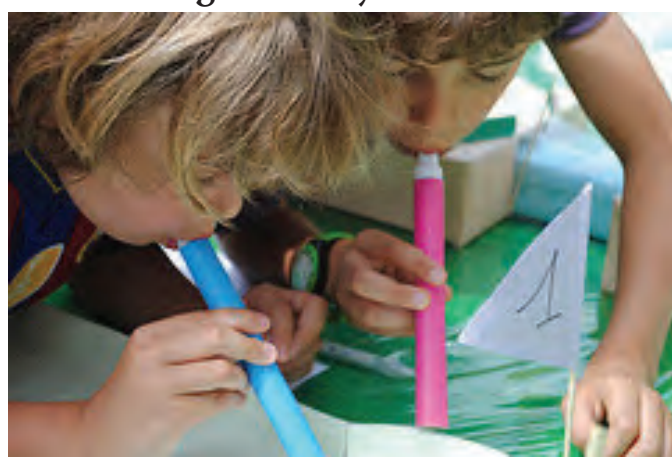

Several countries have coordinated national WSD campaigns to spread the message as widely as possible within their own countries. The Forum of European Respiratory Societies (FERS) and FIRS partners have demonstrated their dedication to public lung health by holding large scale eventsand motivating numerous hospitals and health centres to hold local public testing events. In Germany, the Lungentag, a national annual lung function day, was changed for the first time in 13 years to coincide with WSD, during which, more than 80 events were held. Poland, Portugal , France, Italy, Spain, Turkey, Albania, Czech Republic, Georgia, Belarus, Russia, China, Vietnam, Hong Kong, Slovakia, Romania, Bulgaria, Australia, Kyrgyzstan, Slovenia, Bosnia and Herzegovina, Latvia, North America and
Canada all held national campaigns with up to 64 events across each country! The capital cities of many countries also saw WSD action, including Warsaw, Bucharest, Istanbul, London, Riga, Sofia, Moscow, Minsk, Reykjavik and Brussels.

\section{Having political impact}

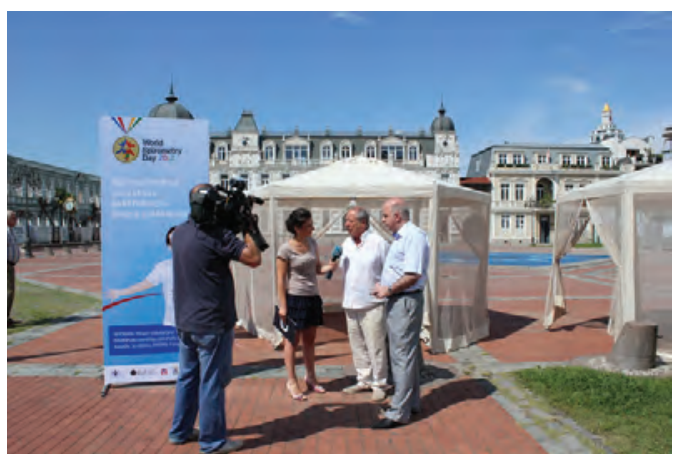

Georgian Respiratory Association's event, where the Mayor and Vice Mayor of Batumi came to get tested.

Some event organisers targeted politicians and government buildings with their message of lung health. In the Czech Republic a National Day of spirometry was held and celebrated with a conference in the Houses of Parliament in Prague. In Italy, politicians and health professionals raised awareness of global lung health issues at a press conference in the Government Building in Rome on June 26. The Parliamentary Secretary for Health in Australia used the occasion to launch two important new National Asthma Council Australia spirometry resources: an Asthma and Lung Function Tests information paper for health professionals and a new patient information brochure, A Guide to Breathing Tests for Asthma. Spirometric testing of Slovak parliament members also took place at the Ministry of health in Slovakia and the Bangladesh Minister for Health launched the WSD campaign in Rangpur.

For full details of all events, please visit the WSD website: www.wsd2O12.european-lung-foundation. org/17520-find-an-event.htm

Photos from events are available at: www.flickr. $\mathrm{com} /$ photos/thekkinkattil 